\title{
The effect of teaching the principles of nursing ethics on the moral turmoil of nurses: a quasi-experimental study
}

\author{
Zohre Zahedi', Mozhgan Rahnama², Mahin Naderifar², Abdolghani Abdollahimohammad², \\ Aziz Shahrakiwahed ${ }^{2}$
}

'MSc Student, Student Research Committee, Nursing and Midwifery School Zabol University of Medical Science, Zabol, Iran ${ }^{2}$ Department of Nursing, Zabol University of Medical Sciences, Zabol, Iran

\section{Abstract}

Introduction: Ethical turmoil causes noteworthy side-effects not only on nurses but also on patients and health organisations. Consequently, among nurses, the issue of ethical turmoil should be given priority as one of the barriers to achieving the goals of the health care system. Thus, this study was performed to determine the effect of teaching ethical principles on nurses' ethical turmoil.

Material and methods: The current study is a quasi-experimental study in which 60 nurses working in one of the hospitals of Zabol city, after random sampling and ensuring that they met the inclusion criteria, were randomly divided into intervention and control groups. Data collection tools were a demographic survey questionnaire and a 36-item moral turmoil questionnaire that was completed before and after the intervention. Data were analysed using SPSS software version 21.

Results: Based on the independent t-test, before the intervention there was no significant difference between the mean score of moral turmoil in the intervention and control groups, but after the intervention, the mean score of moral turmoil changed from $105.13 \pm 37.61$ to $76.47 \pm 40.26$ in the intervention group and from $121.20 \pm 38.26$ to $123.80 \pm 34.82$ in the control group, and there was a significant difference in the mean scores of the 2 groups $(p=0.001)$.

Conclusions: Based on the findings of the current research, the intervention of teaching moral principles can be effective in the moral turmoil of nurses in a sample of Iranian society. These findings, in line with the results of other research, show that the prediction and provision of such educational services in the health care system for nurses is essential and effective.

Key words: teaching, ethics, moral turmoil, nurses.

\section{Address for correspondence:}

Dr Mozhgan Rahnama, Department of Nursing, Zabol University of Medical Sciences, Zabol, Iran, e-mail: morahnama0@gmail.com

\section{INTRODUCTION}

Ethical nursing happens when a good nurse does the right thing [1], but sometimes it is impossible to do the right thing because of organisational pressures. According to Jamiton, moral turmoil appears at this time [2], which is a kind of painful feeling and psychological imbalance $[3,4]$. This phenomenon is a significant issue in the field of nursing and involves nurses in numerous health care centres [5]. Azarm et al. (2017) reported that the level of moral turmoil in nurses was moderate [6]. Also, the results of Barlem et al. (2012) revealed that nurses under their study had the highest understanding of the severity of moral turmoil [7]. In other words, nurses feel particularly prone to moral turmoil because, although they are directly responsible for caring for patients, they do not have the authority to make the final decision [2]. Ethical turmoil has noteworthy effects not only on nurses but also on patients and health organisations [5]. As it results in secondary health problems in patients [8]. On the one hand, it causes the nurse to have conflicts in the field of care and to avoid providing quality care, which provides the ground for defects in the recovery process and enhances the time of hospital stay [9], and on the other hand, nurses under moral turmoil often experience anger, burnout, and guilt, while moral turmoil can result in long-term debilitating effects on their physical and mental health [5]. Some studies have reported the negative influences of moral distress on nurses' physical health in the form of nightmares, insomnia, palpitations, neck pain, feelings of worthlessness, anger, depression, shame, and unhappiness in their professional life [10]. The results 
of Azizi et al. (2014) indicated that there is a significant positive correlation between moral turmoil and components of physical symptoms, anxiety, sleep disorders, social dysfunction, and depression, and moral turmoil can predict nurses' mental health [11]. At the same time, it influences nurses' feelings about their ability to perform tasks and deal efficiently in different situations [12]. The consequences of moral turmoil also affect the organisations, so that the low quality of care increases the length of time patients are hospitalised in medical settings, and organisations face an increase in complaints and dissatisfaction of service recipients. This can result in many financial difficulties for organizations [13]. Some of the most noteworthy problems caused by moral turmoil are the inability to appropriately care for the patient, occasionally leaving work, and changing jobs [5], which eventually exacerbates the shortage of medical staff [8]. So, among nurses, the issue of moral turmoil should be given priority [5] because it is one of the obstacles to achieving the goals of the health care system [10], and it can have a major influence on the quality of patient care, the quality of personal and professional life of caregivers, and finally their efficacy [8]. Azarm et al. (2017) recommended providing training programs and improving the awareness of nurses in the field of moral turmoil [6]. Moreover, Ebrahimi et al. (2013) suggested conducting studies on the effective and predictive factors of moral stress in diverse sectors and educating on strategies to deal with it [8]. Studies in recent years have introduced programs based on teaching ethical principles on moral decision-making as an efficient resource in promoting the level of moral sensitivity [14]. Considering that, on the one hand, there are few ethical items in nurses' training programs in universities and hospitals [15], and, on the other hand, in our country few studies have been done in this field, the current research has been conducted to determine the influence of teaching ethical principles on the moral turmoil of nurses.

\section{MATERIAL AND METHODS}

This quasi-experimental study (pre-test-post-test) with a control group was conducted on 60 nurses of a teaching hospital in Zabol city in Southeastern Iran from February 1, 2020, to September 30, 2020. Inclusion criteria included age 20 to 40 years, having at least a bachelor's degree, at least 2 years of clinical experience, no history of nursing ethics training, and no history of severe stress (death of a loved one, divorce, or severe accident) in the last 4 weeks. Participants were randomly selected and randomly assigned to intervention (30 individuals) and control (30 individuals) groups. The sample size was predicted based on the 2015 study of Mohammadi et al. [17] using the following formula, taking into account the sample loss [18]:

$$
N=2 \mathrm{c} \times\left(\left(\mathrm{Vsd}_{1}^{2}+\mathrm{sd}_{2}^{2} /\left(\mathrm{m}_{1}-\mathrm{m}_{2}\right)\right)^{2}\right.
$$

$N=15.6 \times\left(\left(28.53^{2}+25.54^{2}\right) /(102.67-81.53)\right)^{2}=51.4$

\section{Tools}

To collect data a 2-part questionnaire was used. The first part included demographic characteristics such as age, gender, marital status, level of education, economic status, type of employment, type of ward, position, and work experience, and the second part was the moral turmoil questionnaire. The Standard Moral Turmoil Questionnaire is a 36-item tool that measures the severity of moral distress based on the underlying clinical situation. The validity of this tool has been confirmed in the study of Bikmorad et al. by 17 experts. The reliability of this instrument is confirmed by a Cronbach's alpha of 0.82 [19]. A 7-point Likert scale was used to score each item. The total score for the severity of moral distress is between 0 and 216. Scores 0-72, 73-144, and 145-216 show low, moderate, and severe moral distress, respectively [19].

\section{Ethical considerations}

This research has been approved by the Institutional Review Board (IRB) and Ethics Committee of Zabol University of Medical Sciences (ethics code: IR.ZBMU.REC.1398.112). The aims of the research were clearly presented to the participants, and then the participants were assured that the information was confidential. Written and oral consent was received from the participants.

\section{Intervention}

After explaining the objectives, first, all those who were willing participated, and in the next stage, using random allocation, they were divided into 2 groups: intervention and control. In the intervention group, the participants received the educational content via email and social network (WhatsApp) in 4 sessions with an interval of 5 days. The educational content was presented in the form of explanatory text, PowerPoint, and audio files. After sending the content, receiving the file was confirmed by phone call. The researcher provided the participants with their phone numbers so that they could ask any questions. The educational content included the following: first, the topics of the principles of professional ethics, which include such topics as accountability, continuous competence, professional ethics, knowledge, and its application, leadership, and professional communication. Then, the observance of patients' rights while providing treatment and the participation of the patient and the pateint's family in decisions associated with med- 
ical care were discussed. There was no intervention in the control group, but the nurses of the intervention group were asked to implement the taught items for 1 month, and then 1 month after the end of the last training session the ethical turmoil questionnaire was completed by the nurses again [20].

\section{Statistical analysis}

SPSS V21 software was applied for data analysis. For individual data, descriptive statistics including absolute frequency and frequency percentage, mean and standard deviation were used, and also for comparing qualitative variables between groups, the $\chi^{2}$ test was utilised. Independent t-test and analysis of covariance were applied to check the difference between the mean scores between the 2 groups to control the influence of the pretest. A significance level of 0.05 was considered in this research.

\section{RESULTS}

The mean age of nurses in the intervention and control groups was about 30 years, and the average work experience in the intervention and control groups was about 7 years. The independent t-test did not display a statistically significant difference in mean age $(p=0.810)$ and work experience $(p=0.977)$ between the 2 groups. Likewise, there was no statistically significant difference between the 2 groups in terms of gender, marital status, position, and type of employment $(p>0.05)$ (Table 1).

The results of the Shapiro-Wilk test indicated that the scores of moral turmoil in the intervention and control groups before and after the intervention were normal $(p>0.05)$.

Furthermore, based on the independent t-test, there was no statistically significant difference between the 2 groups before the intervention $(\pi=0.106)$, but after the intervention there was a statistically significant difference between the mean scores of moral turmoil between the 2 groups $(p<0 / 001)$. Also, there was a statistically significant difference between the intervention and control groups by controlling the pre-test variable (before the intervention) (Table 2) $(p<0.001)$.

\section{DISCUSSION}

In the current research, based on the results, the mean score of moral turmoil of nurses before training in the intervention and control groups was estimat-

Table 1. Demographic characteristics of the individuals in the intervention and control groups

\begin{tabular}{|c|c|c|c|}
\hline \multirow[t]{2}{*}{ Variables } & \multicolumn{2}{|c|}{ Groups } & \multirow[t]{2}{*}{$p$-value } \\
\hline & Intervention $(n=30)$ & Control $(n=30)$ & \\
\hline \multicolumn{4}{|l|}{ Gender } \\
\hline Male & $8(26.7)$ & $12(40)$ & \\
\hline Female & $22(73.3)$ & $18(60)$ & 0.273 \\
\hline \multicolumn{4}{|l|}{ Marital status } \\
\hline Single & $8(26.6)$ & $8(26.7)$ & \multirow[t]{3}{*}{0.883} \\
\hline Married & $20(66.7)$ & $22(73.3)$ & \\
\hline Spouse has died & $2(6.7)$ & $0(0)$ & \\
\hline \multicolumn{4}{|l|}{ Education } \\
\hline Bachelors & $28(93.3)$ & $25(83.3)$ & \multirow[t]{2}{*}{0.424} \\
\hline Masters & $2(6.7)$ & 5 (16.7) & \\
\hline \multicolumn{4}{|l|}{ Position } \\
\hline Nurse & $29(96.7)$ & $26(86.7)$ & \multirow[t]{2}{*}{0.126} \\
\hline Head Nurse & $1(3.3)$ & $4(13.3)$ & \\
\hline \multicolumn{3}{|l|}{ Type of employment } & \multirow[t]{5}{*}{0.707} \\
\hline Plan & & $2(6.7)$ & \\
\hline Contractual & $5(16.7)$ & 4 (13.3) & \\
\hline Agreement & $12(40)$ & $11(36.7)$ & \\
\hline Official & $13(43.3)$ & $13(43.3)$ & \\
\hline
\end{tabular}


Table 2. Mean and standard deviation of moral disturbance scores before and after the intervention in the experimental and control groups

\begin{tabular}{lcccc} 
Moral turmoil & \multicolumn{2}{c}{ Groups } & Cl interval & P V \\
\cline { 2 - 4 } & $\begin{array}{c}\text { Intervention } \\
\text { Mean } \pm \text { SD }\end{array}$ & $\begin{array}{c}\text { Control } \\
\text { Mean } \pm \text { SD }\end{array}$ & & \\
\hline Before & $105.13(37.61)$ & $121.20(38.26)$ & $9.79,-3.54$ & 0.1 \\
\hline After & $76.47(40.26)$ & $123.80(34 / .82)$ & $9.72,27.88$ & 0.001 \\
\hline Overall score & $82.11(72.19,92.03)$ & $118.16(108.24,128.07)$ & $21.86,50.23$ & 0.001
\end{tabular}

ed at 105.13 and 121.20 , respectively, which specifies their average level of moral turmoil. Azarm et al. (2017) reported that the amount of moral turmoil in the nurses under their study was moderate [6]. Ameri et al. in 2015 reported that the amount and severity of moral turmoil in the nurses under their study were relatively high [5] Kighobadi et al. (2014) reported that the moral turmoil in the nurses under their study was higher than average [21]. The results of the study of Barlem et al. (2012) indicated that the nurses under their study had the highest understanding of the severity of moral turmoil [7]. Ebrahimi et al. (2013) reported that $53 \%$ of nurses were at a high level of moral stress [8]. All these results suggested that nurses are involved in some degree of moral turmoil and show the need for action to address their moral turmoil. As Behboodi et al. (2018) suggested, professional ethics education planners, in consultation with Islamic experts, should organise and hold professional ethics classes or workshops based on the nurses' needs and according to their religious values [10]. Atashzadeh Shoorideh et al. (2012), at the end of their qualitative study, stated that nursing officials can help nurses to lessen stress, use positive coping methods, and prevent the harmful consequences of stress [22]. Kighobadi et al. (2014) recommended that training, counselling, and familiarising nurses with these components are essential for their ability to deal with moral situations [21].

The researchers of the current study chose to teach ethical principles as a suitable intervention, and the results indicated that after teaching ethical principles of nursing, the mean scores of moral turmoil in the intervention group were reduced significantly. This result can recommend the efficiency of teaching ethical principles of nursing on the moral turmoil of nurses under study. The results of the study of Azizi et al. (2016) also revealed that teaching ethical principles significantly improved the ethical judgment of nurses in the experimental group, and its implementation can help improve the professional competence of nurses [16]. The results of the study of Mohammadi et al. (2015) also indicated that teaching the principles of nursing ethics significantly improved the ethical reasoning of nurses in the intervention group [15]. Also, Mohammadi et al. (2016) stated that after the imple- mentation of an ethics training intervention, a significant decrease was observed in the average scores of nurses in the experimental group under their study. Eventually, they argued that teaching ethical principles can be considered as a factor to enhance moral awareness in nurses and decrease the moral turmoil in them [17]. Hassanpour et al. (2011) also recommended that this training program be implemented for medical staff and nursing students [23].

\section{Limitations}

The main limitations of the current research were the short intervention time because the evaluation of ethical behaviours may take months to develop a new behaviour in the individual. Another limitation was the small sample size, so future research should be conducted on a larger number of participants.

\section{CONCLUSIONS}

According to the findings of the current study, the intervention of teaching ethical principles can be efficient on the moral turmoil of nurses in a sample of Iranian society. These findings, in line with the results of other research, show that the provision of such educational services in the health care system for nurses is necessary and effective.

\section{ACKNOWLEDGMENTS}

This article is derived from the master's thesis at the Faculty of Medical-Surgical Nursing Ethics Code IR.ZBMU.REC.1398.112 in Zabol University of Medical Sciences and nurses. The authors wish to thank Zabol University of Medical Sciences and the nurses participating in this research, as well as all who helped us to perform this research.

\section{REFERENCES}

1. Nikkhah Farkhani Z, Rahiminiya F, Kazemi M, et al. An analysis of nurses' ethical behavior toward persons accompanying 
a patient based on theory of Virtue Ethics. J Qual Res Health 2015; 3: 363-376.

2. Wiggleton C, Petrusa E, Loomis K, et.al. Medical students experiences of moral distress: development of a web - based survey. Acad Med 2010; 5: 111-117.

3. Houston S, Casanova MA, Leveille M, et.al. The intensity and frequency of moral distress among different healthcare diciplines. J Clin Ethics 2013; 24: 98-112.

4. Veer AJE, Francke AL, Struijs A, et al. Determinants of moral distress in daily nursing practice: a cross sectional correlational questionnaire survey. Int J Nurs Stud 2013; 50: 100-108.

5. Ameri M, Mirhashemi B, Hosseini SS. Moral distress and the contributing factors among nurses in different work environments. J Nurs Midwifery Sci 2015; 2: 44-49.

6. Azarm A, Hasanlo M, Hojat Ansari M, et al. Moral distress and the nursing care quality: a correlational study in teaching hospitals. Health Spirit Med Ethics 2017; 4: 38-47.

7. Barlem ELD, Lunard VL, Lunard GL, et al. The experience of moral distress in nursing: the nurses' perception. Rev Esc Enferm USP 2012; 46: 678-685.

8. Ebrahimi H, Kazemi A, Asghari Jafarabadi M, et al. Moral distress in nurses working in educational hospitals of northwest medical of Iran. Iran J Med Ethics 2013; 6: 80-88.

9. Rahimi Golsefid S, Janmohamadi S, Seyed Fatemi N, et al. Effectiveness of end-of-life care education on the moral distress of nurses in neonatal intensive care units. Iran J Pediatr Nurs 2018; 5:75-82.

10. Behbodi M, Sharifpour V, Amiri M. Comparision of moral distress severity between pediatric ward and pediatric intensive care unit nurses. Rel Health 2018; 6: 19-28.

11. Azizi A, Sepahvandi MA, Mohamadi J. Relationship between moral distress and mental health among female nurses. Iran J Nurs 2015; 27: 57-64.

12. Naboureh A, Imanipour M, Salehi T, et al. The relationship between moral distress and self- efficacy among nurses in clinical care and emergency units in hospitals affiliated to Ahvaz Jundishapor University of Medical Sciences in 2015. J Rafsanjan Univ Sci 2015; 14: 443-454.

13. Mohammadi J, Ghadam Pour E, Azizi A. Assessment the relationship between moral turmoil with job demand-control in Tabriz hospitals nurses. J Educ Ethics Nurs 2014; 3: 23-30.

14. Azizi A, Sasanpour M. Effectiveness of nursing ethics training on nurses moral sensivity in 2014. J Clin Nurs Midwifery 2018; 7: 1-8.

15. Mohamadi J, Azizi A. Effectiveness of nursing ethics education on ethical reasoning nurses. Iran J Nurs 2015; 28: 50-57.

16. Azizi A, Sepahvandi MA, Mohamadi J. The effect of nursing ethics education on the moral judgment of nurses. J Nurs Educ 2016; 4: 1-8.

17. Mohamadi J, Ghazanfari F, Azizi A. The effectiveness of ethics training on nurses ethical distress. J Med Educ Dev 2016; 8: 98-104.

18. Abdollahimohammad A, Firouzkouhi M. Sample size estimation in randomized clinical trials (RCTs). J Diabetes Nurs 2019; 7: 737-739.

19. Beikmoradi A, Rabiee S, Khatiban M, et al. Nurses distress in intensive care unit: a survey in teaching hospitals. ijme 2012; 5: 58-69.

20. Khosravi Bonjar A, Saravani-Aval S, Saleh-Moghadam AR, et al. The effect of e-learning on adherence to the therapeutic regimen in patients with type II diabetes. J Diabetes Nurs 2017; 5: 95-109.

21. Keighobadi F, Sadeghi H, Keighobadi F, et al. The relationship between moral distress and emotional exhaustion in nurses. Iran J Med Ethics 2014; 7: 36-47.

22. Atashzadeh Shoorideh F, Ashktorab T, Yaghmaei F. Response of ICU s nurses to moral distress: a qualitative study. Iran J Crit Care Nurs 2012; 4: 159-168.
23. Hassanpoor M, Hosseini M, Fallahi Khoshknab M, et al. Evaluation of the impact of teaching nursing ethics on nurses decision making in Kerman social welfare hospitals in 2011. ijme 2011 ; 4 : 58- 64 . 